\title{
The Kamin blocking effect with variable-duration CSs
}

\author{
ELIZABETH A. KOHLER and JOHN J. B. AYRES \\ University of Massachusetts, Amherst, Massachusetts 01003
}

\begin{abstract}
The role of temporal uncertainty surrounding the time of US occurrence in Kamin's two-stage blocking paradigm was studied. In Stage 1, stimulus A terminated with the onset of a .5-sec, 1-mA shock US; in Stage 2, a compound stimulus, AX, was similarly reinforced. For different groups of eight rats each, the duration of stimulus A and/or AX was either fixed or was varied from trial to trial. When the stimulus duration was fixed, it predicted the exact time of US onset; when it was varied, it did not. We suspected that uncertainty about the moment of US occurrence might enhance US "surprise." If so, then blocking might be attenuated in the varied CS-duration conditions relative to the standard condition in which both A and AX were fixed. Within the range of temporal uncertainty studied here, however, no significant attenuation of blocking was observed.
\end{abstract}

When a target stimulus, $\mathrm{X}$, is reinforced in compound with another stimulus, $A$, conditioning to $X$ will be weaker if $\mathbf{A}$ has itself been previously reinforced than if it has not. In such cases, prior conditioning to A is said to "block" subsequent conditioning to X (Kamin, 1968, 1969).

Most studies of blocking employ a fixed interval between CS onset and US onset. Thus, the CS predicts not only the occurrence of the US, but the exact time of its occurrence as well. Based on Kamin's $(1968,1969)$ notion that conditioning occurs to the extent that the US is surprising, we reasoned that if the AX compound did not predict precisely the time of US onset, blocking might be attenuated. This might be especially true if the A stimulus previously had predicted the exact time of US onset, leading the subjects to "expect" the US at a particular time.

A second basis for believing that uncertainty as to the temporal occurrence of the US in relation to CS onset might be an important factor in blocking was a finding previously described by Rescorla (1971). Rescorla conducted a blocking experiment in which, during A training, the duration of $\mathbf{A}$ was constant across trials, but USs could occur at any time during A's presence. Thus, A predicted USs but not the exact time of their occurrence. Given this unusual feature of Rescorla's procedure, it seemed potentially significant to us that the blocking effect he obtained, though statistically reliable, was much smaller in magnitude than the effects obtained by others using the

This research is based upon a master's thesis by the first author conducted under the direction of the second author. It was supported by Grant MH 28226-01 from the National Institute of Mental Health. Requests for reprints should be addressed to Elizabeth A. Kohler or to John J. B. Ayres, Psychology Department, University of Massachusetts, Amherst, Massachusetts 01003. more conventional procedure (e.g., Gray \& Appignanesi, 1973; Kamin, 1968, 1969).

Based on these two considerations, it seemed possible that uncertainty surrounding the time of US onset both during $\mathrm{A}$ training and during subsequent $\mathrm{AX}$ training could lead to attenuated blocking. In the present study, we manipulated that uncertainty by varying, from trial to trial, the duration of $A$, the $A X$ compound, or both A and the AX compound. These stimuli always terminated in US onset. We compared the blocking produced by these conditions to that produced by a standard condition in which the duration of both $\mathrm{A}$ and $\mathrm{AX}$ was held constant from trial to trial. The experimental conditions were labeled FF, FV, VF, and VV. The first letter indicates whether the A stimulus was fixed or was varied from trial to trial; the second provides the same information about the AX compound. The control conditions were labled $O F$ and $O V$. The $O$ indicates that $A$ training was not given. As in much of the previous work on blocking, the US was electric grid shock, and conditioning was assessed by superimposing the CSs upon an ongoing operant baseline. The strength of conditioning was indexed in terms of the amount of suppression of baseline responding that these CSs evoked.

\section{METHOD}

\section{Subjects}

The subjects were 48 male albino Sprague-Dawley rats from Camm Laboratories, Wayne, New Jersey. On arrival, their weights ranged from 284 to $441 \mathrm{~g}$, with a mean of $356 \mathrm{~g}$. After a week of adaptation to the colony, they were reduced to $80 \%$ of their free-feeding weights and so maintained throughout.

\footnotetext{
Apparatus

The apparatus consisted of six Gerbrands Model $\mathrm{C}$ conditioning chambers, $19.5 \times 23.5 \times 22 \mathrm{~cm}$, housed in sound-attenuating cubicles. A dipper feeder receptacle measuring $5.5 \times 5.0 \times 5.0 \mathrm{~cm}$, was located on the left side of each chamber at floor level.
} 
Mounted on the outside wall of each receptacle was a photocell assembly (Carrigan, Benedict, \& Ayres, 1972) used to record entries of the rat's head (termed "head pokes") into the dipper receptacle. A standard Gerbrands lever, not used in this study, projected into the chamber $7 \mathrm{~cm}$ to the right of the dipper feeder and $8 \mathrm{~cm}$ above the floor. A $28-\mathrm{V}$ cue light, used as one CS, was located directly above the dipper housing, $9.5 \mathrm{~cm}$ above the floor. Two $10-\mathrm{cm}$ speakers were positioned on the chamber lid for the presentation of white noise and tones, but only the tone speaker was used to produce the second CS, a $1,000-\mathrm{Hz}$ tone. Shock USs were provided by a high-voltage, high-resistance shock source and scrambled through a relay-sequencing scrambler (Hoffman \& Fleshler, 1962). Responses were recorded and stimuli were presented by computer in a nearby room.

\section{Procedure}

Preliminary training. On Day 1, each rat was placed in the chamber with a $.1-\mathrm{ml}$ dipper containing $32 \%$ (by weight) sucrose. When the rats had consumed some of the sucrose, they were placed immediately on a random interval 16-sec (RI 16-sec) schedule of reinforcement for head poking. On Day 2, the schedule requirement was raised to RI $32 \mathrm{sec}$ and on Days 3, 4, 5, and 6, to RI $64 \mathrm{sec}$. It remained at RI $64 \mathrm{sec}$ thenceforth. Throughout the study, all sessions were $1 \mathrm{~h}$ in duration and all sucrose presentations were for $4 \mathrm{sec}$.

A training. After 4 days on the RI 64-sec schedule, the experimental groups, Groups FF, FV, VV, and VF, received 4 days of forward conditioning with four conditioning trials daily. For Groups FF and FV, the CS, stimulus A, was a 2 -min illumination of the cue light in the normally dark box. For Groups VF and $V V$, the CS was also the cue light, but its duration varied from trial to trial with a potential range of 2 to $238 \mathrm{sec}$ and a mean of $2 \mathrm{~min}$. CS durations were chosen randomly from the upper and lower fourths of the potential range of durations. The exact values used are shown in Table 1. For all the experimental groups, each CS presentation terminated with the onset of a .5-sec $1-\mathrm{mA}$ grid-shock US. For the control groups, however (Groups OF and OV), no CSs or USs were given during these 4 days, but head poking was reinforced on the RI 64-sec schedule.

On the day following the last A-training session, all groups received a single session in which head poking was reinforced on the RI schedule in the absence of CSs or USs.

AX training. In this phase, all groups received 2 days of forward conditioning with a compound CS consisting of the cue light, stimulus $\mathrm{A}$, presented together with a $1,000-\mathrm{Hz}$ tone, stimulus $\mathrm{X}$. Tone intensities varied from 70 to $82 \mathrm{~dB}\left(\mathrm{re} 20 \mu \mathrm{N} / \mathrm{m}^{2}\right.$ ) across boxes and were presented against a background noise level of $54 \mathrm{~dB}$. For all groups, each of four daily AX presentations terminated with the onset of the .5-sec 1-mA shock US. For Groups OF, FF, and VF, the light + tone duration was fixed at $2 \mathrm{~min}$, while for Groups OV, VV, and FV, it varied from trial to trial, with a potential range of $2-238 \mathrm{sec}$ and a 2 -min mean. Table 1 shows the exact values used. Throughout both $\mathrm{A}$ and $\mathrm{AX}$ training, intertrial intervals were variable and were changed daily. Thus, no temporal cue other than the A or AX stimulus could be used to predict the time of US onset.

Following these conditioning sessions were 2 days in which no CSs or USs were given while the rats head-poked on the RI schedule. These sessions ensured a high and stable rate of responding prior to the critical test phase.

Testing. An extinction test was used to assess conditioning to the tone stimulus, $\mathrm{X}$. Four 2 -min tone presentations were given without USs in a single session while the rats head-poked for sucrose on the RI schedule.

Measure of conditioning. Conditioning to $\mathrm{A}, \mathrm{AX}$, and $\mathrm{X}$ was indexed in terms of the Annau-Kamin (1961) suppression ratio, $D /(B+D)$. Here $D$ denotes the number of head pokes made during a CS presentation, and $B$ denotes the number made in a comparable period before the CS. With this ratio, a score of 0 indicates strong suppression or conditioning, while a score of .5 indicates no effect of the CS.
Table 1

CS Durations in Seconds for Variable Duration Training

\begin{tabular}{crrrr}
\hline & \multicolumn{4}{c}{ Trial } \\
\cline { 2 - 5 } Day & 1 & 2 & 3 & 4 \\
\hline \multicolumn{5}{c}{ A Training } \\
1 & 37 & 213 & 8 & 222 \\
2 & 16 & 51 & 193 & 220 \\
3 & 35 & 15 & 198 & 232 \\
4 & 34 & 212 & 201 & 33 \\
& \multicolumn{5}{c}{ AX Training } \\
1 & 26 & 219 & 17 & 218 \\
2 & 36 & 180 & 44 & 220 \\
\hline
\end{tabular}

Table 2

Results of Training Phases

\begin{tabular}{cccc}
\hline & \multicolumn{3}{c}{ Mean Suppression Ratio } \\
\cline { 2 - 4 } Group & $\begin{array}{c}\text { A Training } \\
\text { Last Day }\end{array}$ & First Trial & Last Day Training \\
\hline FF & .04 & .03 & .03 \\
FV & .06 & .03 & .03 \\
VF & .04 & .01 & .06 \\
VV & .03 & .02 & .02 \\
OF & & .32 & .10 \\
OV & & .15 & .14 \\
\hline
\end{tabular}

\section{RESULTS}

During A training, all experimental groups acquired suppression at the same rate and reached similar terminal levels; the latter are shown in Table 2. A Groups by Trials analysis of variance performed on the acquisition data found no significant effect of Groups or the Groups by Trials interaction (Fs $<1$ ). During AX training, the four experimental groups for which A had been pretrained suppressed more to the first AX compound presentation than did the two control groups, Groups OF and OV, for which both stimuli were novel $[t(42) \mathrm{s} \geqslant 3.40$, ps $<.01]$. Also, as Table 2 suggests, Group OV suppressed more than did Group OF $[\mathrm{t}(42)=2.57, \mathrm{p}<.05]$. This greater suppression in Group OV probably occurred because the first AX presentation for Group OV was only $26 \mathrm{sec}$ long; therefore novelty effects had little time to adapt out (cf. Ayres, 1965, p. 30). By the end of AX training (Table 2), all groups were suppressing at similar levels. Differences among groups were not reliable $[F(5,42)=2.00, p=.10]$. The suggestion of weaker conditioning in Groups $\mathrm{OF}$ and $\mathrm{OV}$ in Table 2 is misleading in that two rats in each of these groups had depressed pre-CS baseline rates that contributed to highly inflated suppression ratios on one trial.

Of greater interest than the results of the training phases are the results of the final extinction test of the conditioned strength of stimulus $\mathrm{X}$. These results 


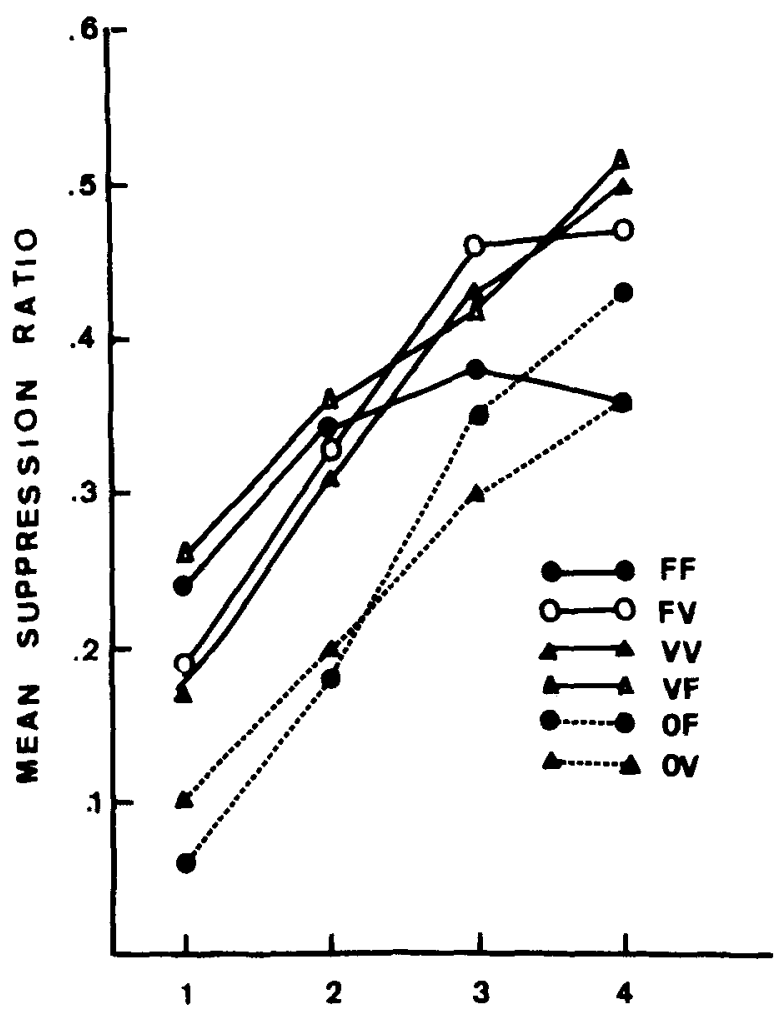

TRIAL

Figure 1. Group mean suppression ratios for the four trials of the extinction test.

are shown in Figure 1. The figure suggests that conditioning to $\mathbf{X}$ was weaker in the four experimental groups than in the two controls. This impression is supported by the results of a 3 by 2 by 4 mixeddesign analysis of variance in which the variables were A-training treatment $(\mathrm{O}, \mathrm{F}$, or $\mathrm{V})$, AX-training treatment ( $F$ or V), and trials. Only the effects of the Atraining treatments $[F(2,42)=4.77, p<.01]$ and trials $[F(3,126)=70.32, p<.01]$ were reliable. Follow-up planned comparisons performed on the data of the first two test trials indicated that each experimental group showed a blocking effect with respect to the OF control group [t $(42) \mathrm{s} \geqslant 2.80$, ps $<$ .011 . Also, Groups FF and VV showed blocking relative to Group OV [t(42)s $=2.20$, ps $<.05]$. The two control groups did not differ from each other, and the four experimental groups did not differ among themselves [t(42)s $\leqslant .60$, ps $>.60]$. In summary, all four experimental groups showed evidence of blocking, and no evidence of unblocking was found in any groups with variable CS duration training.

During the extinction test, the mean pre-CS baselines were $55,62,54,62,61$, and 58 responses $/ \mathrm{min}$ for Groups FF, FV, VF, VV, OF, and OV, respectively. These rates did not differ significantly $(F<1)$, indicating that the differences in suppression just described were not complicated by differences in the baseline response rates.

\section{DISCUSSION}

The main contribution of the present findings is to extend the generality of the blocking phenomenon: blocking appears to occur under a fairly wide variation in the CS duration from trial to trial. Like Rescorla's (1971) results, the present data show that blocking can indeed be obtained when the time of US onset is poorly predicted by stimulus A. They extend Rescorla's findings by showing that blocking can also be produced when the time of US occurrence is poorly predicted by the compound stimulus, $\mathrm{AX}$, and by both stimulus $\mathrm{A}$ and the $\mathrm{AX}$ compound. Further, the blocking effect noted here for Groups FV, VF, and VV was not detectably different from that seen in Group FF. This suggests that the relatively weak blocking effect Rescorla observed was not due to the uncertainty surrounding the time of US presentation during stimulus $\mathrm{A}$ as suggested in our introduction.

The blocking effect we observed in all of our groups was comparable in magnitude to that found by Rescorla and smaller than that noted by Gray and Appignanesi (1973) and Kamin (1968, 1969). A procedural feature that our study shared with Rescorla's but not with Kamin's or with Gray and Appignanesi's was the use of operant recovery training between the end of $\mathbf{A}$ training and the start of AX training. This recovery training necessarily involved nonreinforced exposure to apparatus cues possibly made excitatory during the A-training phase. Such exposure could have led to the extinction of any excitation conditioned to these cues and would thus have removed a potential source of blocking during the AX-training phase. Perhaps, then, conditioning to background cues during the training of stimulus A contributed to the robust blocking effects obtained by Gray and Appignanesi and by Kamin.

Finally, we had suspected that by making the exact time of USs unpredictable, we might enhance US surprise and thus attenuate blocking. Within the range of the temporal variability we studied, however, no significant attenuation of blocking was observed. Since, in this study, we had no measure of surprise independent of the presence or absence of blocking, it is impossible to decide whether our manipulation was unsuccessful in enhancing surprise or whether surprise is not critical in attenuating blocking.

\section{REFERENCES}

AnnaU, Z., \& Kamin, L. J. The conditioned emotional response as a function of intensity of the US. Journal of Comparative and Physiological Psychology, 1961, 54, 428-432.

AyRES, J. J. B. Conditioned suppression and the Egger-Miller information hypothesis. Unpublished doctoral dissertation, University of Kentucky, 1965.

Carrigan, P. F., Benedict, J. O., \& Ayres, J. J. B. A comparison of leverpress and head-poke discriminated Sidman 
avoidance. Behavior Research Methods \& Instrumentation, 1972, 4, 301-303.

Gray, T., \& Appignanesi, A. A. Compound conditioning: Elimination of the blocking effect. Learning and Motivation, 1973, 4, 374-380.

Hoffman, H. S., \& Fleshlen, M. A relay sequencing device for scrambling grid shock. Journal of the Experimental Analysis of Behavior, 1962, 5, 329-330.

KAMIN, L. J. "Attention-like" processes in classical conditioning. In M. R. Jones (Ed.), Miami symposium on the prediction of behaivor, 1967: Aversive stimulation. Coral Gables, Fla: University of Miami Press, 1968.
KamiN, L. J. Predictability, surprise, attention and conditioning. In B. A. Campbell \& R. M. Church (Eds.), Punishment and aversive behavior. New York: Appleton-Century-Crofts, 1969.

Rescorla, R. A. Variation in the effectiveness of reinforcement and nonreinforcement following prior inhibitory conditioning. Learning and Motivation, 1971, 2, 113-123.

(Received for publication July 28, 1978; revision accepted November 6, 1978.)

\section{ERRATUM to Miller, Marlin, and Berk}

In the article, "Reliability and Sources of Control of Preference for Signaled Shock," by R. R. Miller, N. A. Marlin, and A. M. Berk (Animal Learning \& Behavior, 1977, 5, No. 3, 303-308), an error appears on page 306. Line 9 of the left-hand column reads "5-sec scrambled footshock ...." It should read ".5-sec scrambled footshock ...." 